\title{
Current and Emerging Classes of Pharmacological Agents for the Management of Hypertension
}

\author{
Utkarsh Ojha ${ }^{1}$ (D) Sanjay Ruddaraju ${ }^{2} \cdot$ Navukkarasu Sabapathy $^{3} \cdot$ Varun Ravindran $^{4} \cdot$ Pitchaya Worapongsatitaya $^{5}$. \\ Jeesanul $\mathrm{Haq}^{6} \cdot$ Raihan Mohammed $^{7} \cdot$ Vinod Patel $^{8}$
}

Accepted: 24 October 2021 / Published online: 8 December 2021

(c) The Author(s), under exclusive licence to Springer Nature Switzerland AG 2021

\begin{abstract}
Cardiovascular disease accounts for more than 17 million deaths globally every year, of which complications of hypertension account for 9.4 million deaths worldwide. Early detection and management of hypertension can prevent costly interventions, including dialysis and cardiac surgery. Non-pharmacological approaches for managing hypertension commonly involve lifestyle modification, including exercise and dietary regulations such as reducing salt and fluid intake; however, a majority of patients will eventually require antihypertensive medications. In 2020, the International Society of Hypertension published worldwide guidelines in its efforts to reduce the global prevalence of raised blood pressure (BP) in adults aged 18 years or over. Currently, several classes of medications are used to control hypertension, either as mono- or combination therapy depending on the disease severity. These drug classes include those that target the renin-angiotensin-aldosterone system (RAAS) and adrenergic receptors, calcium channel blockers, diuretics and vasodilators. While some of these classes of medications have shown significant benefits in controlling BP and reducing cardiovascular mortality, the prevalence of hypertension remains high. Significant efforts have been made in developing new classes of drugs that lower BP; these medications exert their therapeutic benefits through different pathways and mechanism of actions. With several of these emerging classes in phase III clinical trials, it is hoped that the discovery of these novel therapeutic avenues will aid in reducing the global burden of hypertension.
\end{abstract}

\section{Key Points}

Globally, there are 1.3 billion patients with hypertension,

Utkarsh Ojha

utkarshojha@hotmail.com

1 Department of Cardiology, Royal Brompton and Harefield Hospitals, Hill End Rd, Harefield UB9 6JH, UK

2 James J. Peters Veterans Affairs Medical Center, Bronx, NY, USA

3 Saveetha Medical College and Hospital, Chennai, Tamil Nadu, India

4 CMEF (Canton Medical Education Foundation), Canton, $\mathrm{OH}$, USA

5 Department of Medicine, University of Minnesota, Minnesota, MN, USA

6 Institute of Applied Health Sciences, University of Science and Technology Chittagong, Chittagong, Bangladesh

7 Croydon University Hospitals NHS Trust, London, UK

8 Department of Cardiology, The Mount Sinai Hospital, New York City, NY, USA of whom fewer than one in five have their blood pressure (BP) under control.

While several drug classes are available for the management of raised $\mathrm{BP}$, the prevalence of hypertension continues to increase in pandemic proportions.

New research has identified novel pathways and mechanisms for lowering BP.

Despite the disruption caused by the severe acute respiratory syndrome coronavirus 2 (SARS-CoV-2) pandemic in the conception, development and delivery of these novel drugs, several agents in preclinical trials are showing considerable promise in adequately controlling raised BP. 


\section{Introduction}

Hypertension is a multifactorial, complex disorder estimated to affect one in three adults in the United States (US) [1]. Globally, the prevalence of hypertension is expected to reach 1.6 billion by 2025 [2]. Several factors influencing elevated blood pressure (BP) have been identified. Modifiable risk factors affecting BP include diet, obesity, smoking and physical exercise, while non-modifiable factors include increasing age, sex and genetics. Adequately controlling high BP reduces the risk of stroke, coronary artery disease, peripheral vascular disease, congestive heart failure and end-stage renal failure. The risk of developing these complications can start at a BP level as low as $115 / 75 \mathrm{mmHg}$ [3]. In 2017, the American College of Cardiology (ACC) and American Heart Association (AHA) released updated guidelines in which they lowered the traditional BP cut-off value for diagnosing hypertension (Table 1) [4]. Accurately diagnosing hypertension can still pose significant challenges for physicians, as BP readings can fluctuate unexpectedly, a phenomenon referred to as labile hypertension. In 2020, the International Society of Hypertension produced global guidelines to enable physicians to diagnose and manage hypertension as accurately as possible [5]. These guidelines classified hypertension based on systolic and diastolic cutoffs, taking into account the manner and environment in which the BP measurements were taken.

The exact pathophysiology of hypertension remains largely unknown. It is thought that up to $5 \%$ of patients with hypertension have either renal or adrenal system impairment. In the remainder of patients, the cause is not entirely clear and these patients are labelled as having 'essential hypertension'. The regulation of BP relies on cardiac output and systemic vascular resistance. Most patients with essential hypertension have normal cardiac output but raised peripheral resistance. Peripheral resistance is determined by the small arterioles which contain smooth muscle. A rise in intracellular calcium leads to contraction of these smooth muscles, which in turn raises peripheral resistance. The autonomic nervous system is also thought to play an

Table 1 Stages of hypertension as defined by the ACC/AHA [4]

\begin{tabular}{ll}
\hline Stage & Blood pressure $(\mathrm{mmHg})$ \\
\hline Normal & $<120 /<80$ \\
Elevated & $120-129 /<80$ \\
Stage 1 & $130-139 / 80-89$ \\
Stage 2 & $\geq 140 / \geq 90$ \\
Hypertensive crisis & $>180 />120$ \\
\hline
\end{tabular}

ACC American College of Cardiology, AHA American Heart Association important role in increasing BP. Sympathetic nervous system (SNS) stimulation can lead to an increase in cardiac output and both arteriolar constriction and dilation. The SNS has an important function in short-term changes in BP that occur in response to physical exercise, however there is a lack of evidence suggesting its involvement in the development of chronic hypertension. It has also been suggested that endothelial dysfunction can lead to essential hypertension. Currently available antihypertensive agents exert their therapeutic effect by altering these underlying pathologic processes. These drug classes include those that target the renin-angiotensin-aldosterone system (RAAS), adrenergic receptors, and calcium channel blockers (CCBs), and induce diuresis and vasodilation. The increasing global incidence and burden of hypertension and its associated complications has necessitated the development of novel drugs with greater safety and efficacy than existing treatments.

\section{Current Pharmacological Classes of Antihypertensive Agents}

\subsection{Drugs Targeting the Renin-Angiotensin-Aldosterone System (RAAS)}

\subsubsection{Angiotensin-Converting Enzyme Inhibitors (ACEi)}

The angiotensin-converting enzyme (ACE) is an enzyme produced primarily by the pulmonary vasculature. Upon conversion of angiotensinogen to angiotensin (AT) I by renin, ACE catalyses the conversion of AT I to AT II (Fig. 1). AT II causes vasoconstriction and stimulates the release of aldosterone from the Zona Glomerulosa of the adrenal gland, which in turn leads to $\mathrm{Na}^{+}$and water reabsorption and rise in blood volume. The observation that snake bite caused people to collapse due to a rapid decrease in BP led to the hypothesis that snake venom may induce its antihypertensive properties by inhibiting this pathway. The relationship between ACE, AT I, AT II and snake venom eventually led to the development of the first ACEi, captopril [6]. ACEi are one of the recommended first-line agents for those with uncontrolled stage 1 hypertension and non-Black patients [7]. Commonly used ACEi include benazepril, enalapril, fosinopril, lisinopril, moexipril, perindopril, quinapril, ramipril and trandolapril. The dosage of ACEi varies by medication and population subgroups. Common adverse effects of ACEi include hypotension, therefore these drugs should not routinely be used concurrently with other drugs that suppress the RAAS, such as angiotensin receptor blockers (ARBs) or renin inhibitors. Due to their effect on decreased bradykinin breakdown, ACEi are contraindicated in patients with a history of angioedema. ACEi are known teratogens and are 


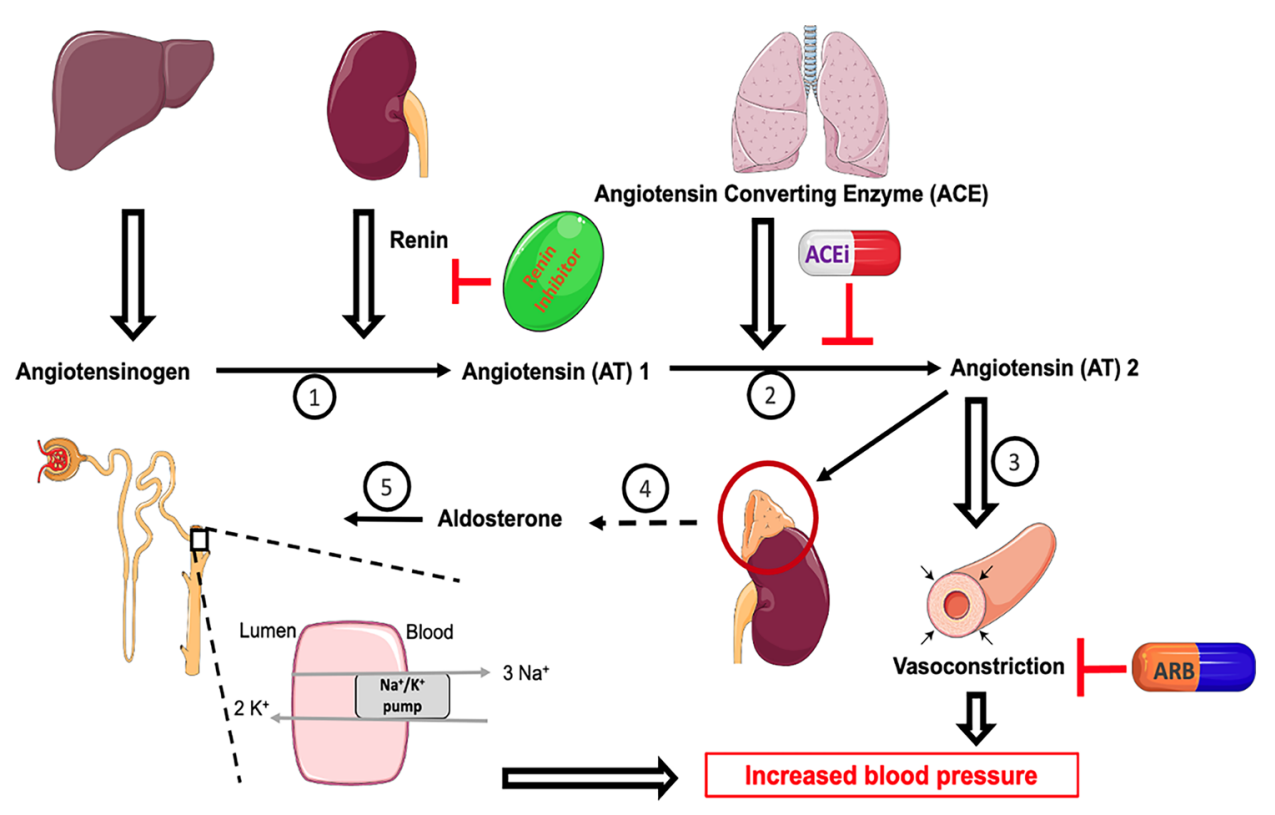

Fig. 1 Mechanism of action of angiotensin converting enzyme inhibitors and angiotensin receptor blocker on The renin-angiotensin-aldosterone system (RAAS). The liver secretes angiotensinogen which is then converted to angiotensin 1 via the action of renin (1), which is released by the kidneys. Angiotensin 1 is subsequently converted into its active component (2) angiotensin 2 via the action of angiotensin converting enzyme, which is produced by the pulmonary vasculature. Angiotensin 2 increases blood pressure via two mechanisms: angiotensin 2 by itself is a potent vasoconstrictor (3) which

therefore to be avoided in pregnant women. Moreover, caution is required when using ACEi in patients with bilateral renal artery stenosis due to a risk of acute renal failure. Further common adverse effects include dry cough and hyperkalemia and there have also been reports of gynecomastia, agranulocytosis and eosinophilic pneumonitis [8].

\subsubsection{Angiotensin Receptor Blockers (ARBs)}

AT II binds to the $\mathrm{AT}_{1}$ subtype of AT II receptors, which are present predominantly in the heart, liver, kidneys, adrenal glands and brain. Activation of these receptors increase cardiac contractility, sodium reabsorption and vasoconstriction, which in turn leads to an increased blood volume and BP. Attempts have been made to develop AT II receptor antagonists to block the receptor and lower BP [9]. These studies resulted in the development of the first ARB, losartan. Other examples of commonly used ARBs include azilsartan, candesartan, eprosartan, irbesartan, olmesartan, telmisartan and valsartan. Because of their excellent tolerability profile, ARBs are one of the first-line drugs for treating hypertension. The JNC-8 guidelines suggest using ARBs as monotherapy or in combination with thiazide diuretics and dihydropyridine CCBs in non-Black populations. These guidelines also advise the use of ACEi or ARBs as increases systemic blood pressure. Furthermore, angiotensin 2 acts on the adrenal cortex to release aldosterone from the zona glomerulosa (4). Aldosterone acts on the collecting ducts and distal convoluted tubules (DCT) to facilitate sodium ion reabsorption by acting on the sodium-potassium pump (5); water is also reabsorbed in conjunction with sodium ions during this process (not shown). The reabsorption of sodium ions and water increases intravascular volume thereby increasing blood pressure

a first-line option, regardless of ethnicity, for patients with chronic kidney disease (CKD) [7]. There is an estimated reduction of $8 \mathrm{mmHg}$ for systolic $\mathrm{BP}(\mathrm{SBP})$ and $5 \mathrm{mmHg}$ for diastolic BP (DBP), similar to ACEi [10]. The most frequent adverse effects with ARBs include dizziness, headache, and hyperkalemia, while uncommon adverse effects include first-dose hypotension, rash, diarrhoea, dyspepsia, abnormal liver function, muscle cramps, myalgias, back pain, insomnia, decreased hemoglobin, renal impairment, pharyngitis, and nasal congestion [11]. The occurrence of dry cough with ARBs is significantly lower compared with ACEi [12]. In general, withdrawal due to adverse effects is significantly less in patients taking ARBs compared with ACEi [11]. ARBs are contraindicated in patients with bilateral renal artery stenosis because they can precipitate renal failure. Elevated AT II in bilateral RAS helps maintain the glomerular filtration rate (GFR) and administration of ARBs can neutralize this beneficial effect [13]. Although there is no conclusive evidence to demonstrate the cross-reactivity of angioedema between ACEi and ARBs in patients with ACEi-induced angioedema, caution must be exercised [14]. 


\subsubsection{Renin Inhibitors}

Renin inhibitors bind to the active site of the renin molecule and prevent the binding of renin to angiotensinogen, which is the rate-limiting step of the RAAS cascade. This action prevents the formation of AT I and II. The first and only drug from this class to be approved for use is aliskiren, which has been approved for the treatment of mild to moderate hypertension. In experimental and clinical studies, aliskiren has been shown to reduce BP in a dose-dependent manner $[15,16]$. A Cochrane review of randomized controlled trials (RCTs) conducted on aliskiren concluded that the mean reduction in BP with $300 \mathrm{mg}$ was almost similar to other classes of antihypertensives [17]. Non-serious adverse effects commonly seen with this drug are headache, diarrhoea, dizziness and fatigue; hypotensive episodes were seen in volume-depleted patients. Further contraindications include aliskiren's concurrent use with ACEi or ARBs in diabetic patients. Despite its potent antihypertensive properties, alikiren is not considered a mainstay option for pharmacological management of hypertension. Research into developing agents in this class with better bioavailability and tissue availability is ongoing.

\subsection{Calcium Channel Blockers (CCBs)}

CCBs are a versatile class of drugs, which can be broadly categorized into two subtypes-dihydropyridines and nondihydropyridines. Both dihydropyridines and non-dihydropyridines act by inhibiting the voltage-gated L-type calcium channels; the former class acts more on vascular smooth muscle and the latter is more cardioselective. By impeding the entry of extracellular $\mathrm{Ca}^{2+}$ into vascular smooth muscle, CCBs decrease excitation-contraction coupling and thus decrease peripheral vascular resistance and BP. In cardiac myocytes, these agents decrease sinoatrial nodal activity and atrioventricular conduction. Current examples of dihydropyridines that are commonly used for hypertension include amlodipine, nifedipine, felodipine, nicardipine, cilnidipine, while examples of non-dihydropyridines that are commonly used include verapamil and diltiazem (Fig. 2). The ALLHAT study reported that compared with lisinopril, amlodipine yields a $1.2 \mathrm{mmHg}$ lower SBP [18]. The VALUE trial found a greater decrease in SBP and DBP, by 4.0 and $2.1 \mathrm{mmHg}$, respectively, with amlodipine than with valsartan after 1 month, and by 1.5 and $1.3 \mathrm{mmHg}$, respectively, after 1 year [19]. According to the JNC-8 criteria, along with ACEi or ARBs and thiazide diuretics, CCBs are indicated as a first-line management of high BP [7]. The ALLHAT study further found that $\mathrm{CCB}$ s are preferred over ACEi for the management of hypertension in patients of Afro-Caribbean origin because of the higher rates of stoke, peripheral artery disease and hospitalization due to angina among these patients in the ACEi group [18]. Common adverse effects of dihydropyridine CCBs include peripheral oedema, flushing, tachycardia, and dizziness. Non-dihydropyridine CCBs have an inhibitory effect on cardiac tissue and thus cause cardiac depression and atrioventricular block; verapamil has been known to cause constipation [20]. Rarely, both dihydropyridine CCBs and non-dihydropyridine CCBs can cause gingival hyperplasia, oesophageal dysfunction, and mild elevation of hepatic transaminases [21]. CCBs are contraindicated in patients allergic to any component of the medication and are also contraindicated in patients with severe hypotension, sick sinus syndrome, second- or third-degree heart block,
Fig. 2 Commonly used calcium channel blockers (CCBs). CCBs can be categorised into dihydropyridine, which primarily act on vascular smooth muscle and non-dihydropyridine agents. Non-dihydropyridine CCBs can be further classified into phenylalkylamines, which are more selective for the myocardium, and benzothiazepine, which have both myocardium depressant and vascular smooth muscle relaxant properties

\section{Calcium Channel Blockers}

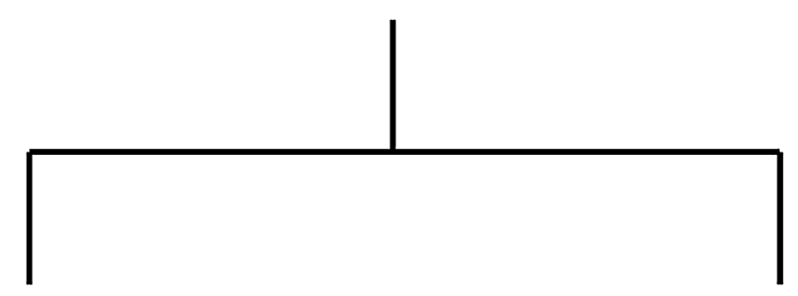

\section{Dihydropyridine}

- Amlodipine

- Cilnidipine

- Felodipine

- Lacidipine

- Lercanidipine

- Nicardipine

- Nifedipine

- Nimodipine
Non-Dihydropyridine

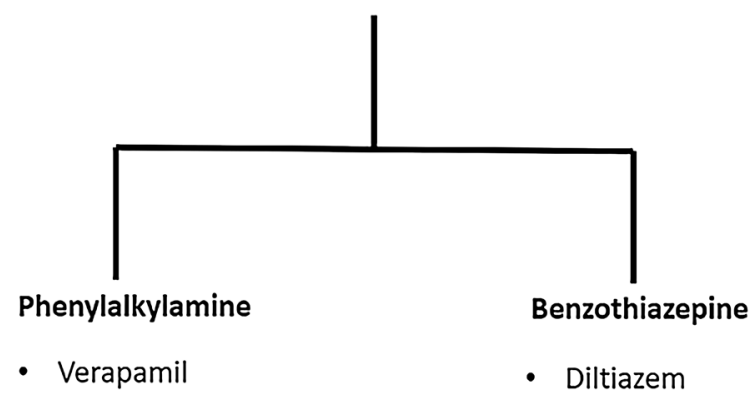



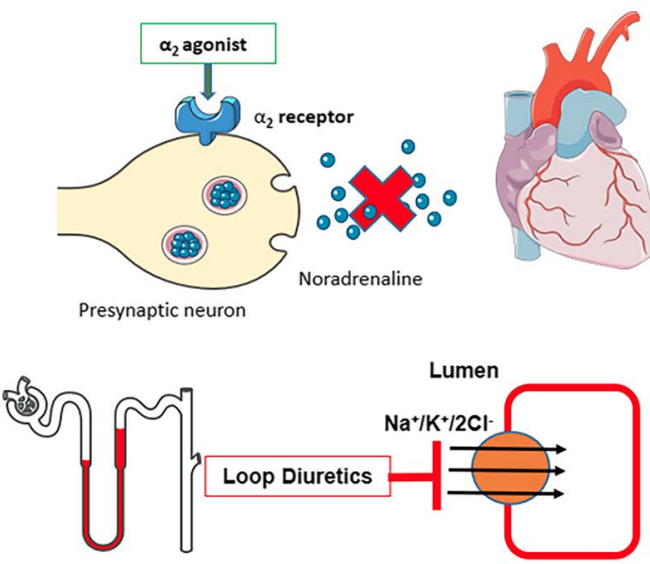

Thick Ascending Loop of Henle

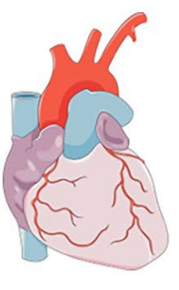

Heart

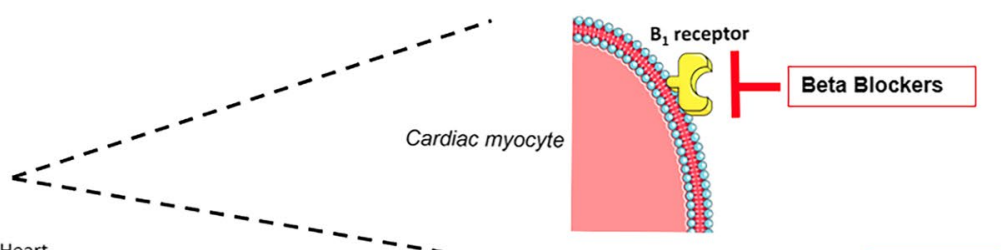

art

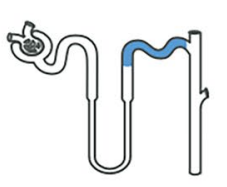

Distal Convoluted Tubule

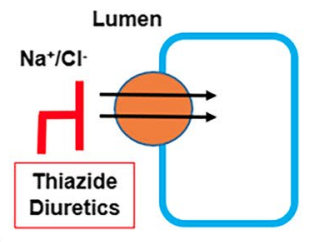

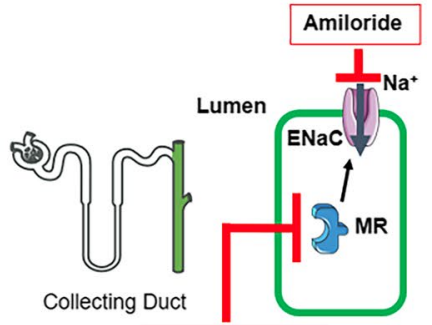

Spironolactone
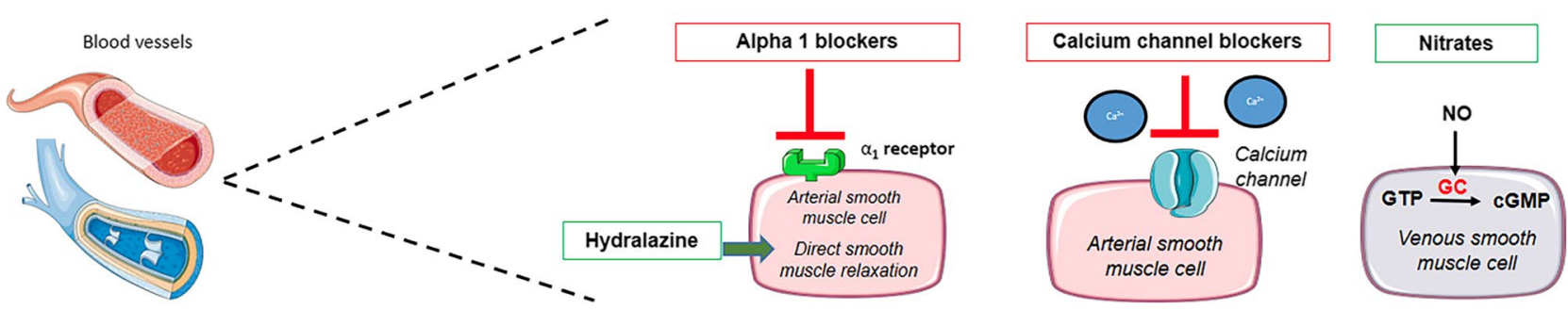

Fig. 3 Sites of action of current classes of antihypertensive medications (ACEi and ARB shown in Fig. 1) $c G M P$ cyclic guanosine monophosphate, $G C$ guanylyl cyclase, GTP guanosine triphosphate, $M R$ Mineralocorticoid Receptor, $N O$ nitric oxide

and patients with an accessory bypass tract, acute myocardial infarction (MI) or pulmonary congestion [22].

\subsection{Diuretics}

Diuretics are a vast group of drugs that can be further subdivided into carbonic anhydrase (CA) inhibitors, loop diuretics, thiazides, potassium-sparing diuretics, and osmotic diuretics. Loop diuretics, thiazides and potassiumsparing diuretics are all indicated for the management of high BP, however thiazides and thiazide-like diuretics are more commonly used. Although all diuretics induce a natriuretic action and block $\mathrm{Na}^{+}$reabsorption, they do so at different parts of the nephron by inhibiting various transporters (Fig. 3). Loop diuretics, such as furosemide and torasemide, work at the thick ascending limb of the loop of Henle and block the $\mathrm{Na}^{+}-\mathrm{K}^{+}-2 \mathrm{Cl}^{-}$transport protein. Thiazides such as hydrochlorothiazide and chlortalidone act at the distal convoluted tubule and inhibit the $\mathrm{Na}^{+} \mathrm{Cl}^{-}$cotransporter. Potassium-sparing diuretics, which work at the collecting duct, can be divided into two categories: teridine analogues, such as amiloride and triamterene, inhibit reabsorption of $\mathrm{Na}^{+}$via the epithelial $\mathrm{Na}^{+}$ channel (ENaC), and the aldosterone receptor antagonists spironolactone and eplerenone are inhibitors of aldosterone at the mineralocorticoid receptor. In recent studies, it was found that thiazides reduced SBP and DBP by 9 $\mathrm{mmHg}$ and $6 \mathrm{mmHg}$, respectively, compared with placebo. They have further been shown to reduce pulse pressure by 4-6 mmHg, which is greater than the reduction caused by ACEi, ARBs, renin inhibitors, or $\beta$-blockers (BBs) [23]. Common adverse effects of loop diuretics include ototoxicity, hypokalemia, hypomagnesemia and metabolic alkalosis, whereas adverse effects of thiazides include hyponatremia, hyperglycemia, hyperlipidemia, hyperuricemia, and hypercalcemia. While all potassium-sparing diuretics can lead to hyperkalemia, aldosterone receptor antagonists can lead to gynecomastia and decreased libido. Diuretics are contraindicated in patients allergic to any component of the medication as well as those with hepatic and renal failure. Loop diuretics are contraindicated in gout and pregnancy, thiazides are contraindicated in gout, and potassium-sparing diuretics are contraindicated in patients with hyperkalemia and in those taking ACEi or ARBs, and in pregnancy [24]. 


\subsection{Drug Classes Targeting Adrenergic Receptors}

\subsection{1 $\beta$-Blockers}

BBs are a class of drugs consisting of many subtypes, each with different pharmacokinetic and pharmacodynamic properties. Some of the mechanisms include a reduction in cardiac output by competitively blocking $\beta 1$ receptors in the cardiac myocytes, which inhibits the signal transduction pathway of Gs protein, resulting in negative inotropic and chronotropic effects (Fig. 2). BP-lowering properties are also seen when $\mathrm{BBs}$ act on $\beta 1$ receptors in the kidneys, resulting in inhibition of renin release from juxtaglomerular apparatus and subsequent decrease in AT II and aldosterone production, enhancing renal loss of $\mathrm{Na}^{+}$and water and further diminishing arterial pressure. Several trials in the 1990s showed the efficacy of BBs compared with placebo in managing hypertension with a 4-27 $\mathrm{mmHg}$ drop in SBP $[25,26]$. However, the efficacy of BB use in uncomplicated hypertension was first questioned by two large hypertension trials: the Losartan Intervention for End Point Reduction in Hypertension (LIFE) study and the Anglo-Scandinavian Cardiac Outcomes Trial-Blood Pressure Lowering Arm (ASCOT-BPLA), which found superiority of losartan and amlodipine, respectively, compared with atenolol [27, 28]. Many clinical trials and meta-analyses have demonstrated that BBs are inferior to other antihypertensive drugs on cardiovascular protection for several reasons, including their suboptimal BP-lowering efficacy [27-29], their inability to adequately lower central aortic pressure [30], their reduced effect on left ventricular hypertrophy regression [31], and their unfavourable metabolic effects [32]. A meta-analysis including all studies on cardiovascular mortality and morbidity revealed that first-line BB therapy reduced the risk of stroke, but to a lesser extent when compared with other agents, including low- and high-dose thiazide, ACEi, or CCBs [33]. Some examples of $\beta 1$-selective BBs include atenolol, bisoprolol and metoprolol. The fact that more than $75 \%$ of the data in previous meta-analyses were from studies where atenolol was the main agent of interest increases the risk of selection biases and raises questions whether the lack of therapeutic benefit with BB is a class effect or is limited to atenolol $[34,35]$. Due to the diversity in the location of the $\beta$ receptors, BBs result in many adverse effects, including drowsiness, lethargy, sleep disturbance, visual hallucinations, depression, blurring of vision, nightmares, bronchospasm in asthmatic patients, peripheral vascular effects such as cold extremities, Raynaud's phenomenon, erectile and orgasmic dysfunction and masking of hypoglycemic symptoms such as tachycardia [36]. Although BBs are contraindicated in patients with asthma, recommendations have supported the use of $\beta 1$-selective BBs in this group of patients [4]. Other contraindications include patients with cocaine-induced coronary vasospasm, acute or chronic bradycardia and/or hypotension, long QT-syndrome, and previous Torsades de Pointes.

\subsection{2 a-Blockers}

Although the use of $\alpha$-blockers in the management of primary hypertension is limited, they play a significant role in the management of secondary hypertension and benign prostatic hyperplasia (BPH). The combined treatment of hypertension and BPH has made $\alpha$-blockers an attractive option. $\alpha$ Receptors are categorized into two subtypes- $-\alpha 1$ and $\alpha 2$. $\alpha 1$ receptors primarily involve smooth muscle contractions causing vasoconstriction (Fig. 3) of the blood vessels, ureter, vas deferens, urothelium and several other areas. $\alpha 1$ is the primary receptor for the control of hypertension and BPH. Current examples of selective $\alpha 1$-blockers include doxazosin, prazosin, terazosin and tamsulosin; non-selective $\alpha$-blockers include phentolamine and phenoxybenzamine. In a Cochrane meta-analysis comparing the BP-lowering efficacy of $\alpha$-blockers with placebo, doxazosin, on average, lowered SBP by $6.42 \mathrm{mmHg}$ and DBP by $3.53 \mathrm{mmHg}$, prazosin lowered SBP by $10.38 \mathrm{mmHg}$ and DBP by $6.90 \mathrm{mmHg}$, and terazosin lowered SBP by $6.59 \mathrm{mmHg}$ and DBP by $4.40 \mathrm{mmHg}$ [37]. The primary goal of the ALLHAT trial was to find the rate of fatal coronary heart disease (CHD) and non-fatal MI, and the secondary goal was to study the rate of cardiovascular disease events. Whereas patients receiving doxazosin and chlortalidone had similar rates of fatal CHD and non-fatal MI, it was found that those taking doxazosin had a higher incidence of congestive heart failure compared with those taking chlortalidone (8.13\% vs. $4.45 \%$ at 4 years; $p<0.001)$. Therefore, the doxazosin arm of the trial was terminated [38]. The efficacy of $\alpha$-blockers on BPH was documented in the MTOPS trial [39] and the COMBAT study [40]. In the MTOPS trial, complications such as acute urinary retention, urinary incontinence, renal insufficiency, or recurrent urinary tract infections were reduced, compared with placebo, by $39 \%$ with doxazosin, 34\% with finasteride, and $66 \%$ with combination therapy [39]. Phentolamine has been administered during medical management of pheochromocytoma acute hypertensive attacks [41] and phenoxybenzamine is commonly administered prior to surgery [42]. A common adverse effect of $\alpha$-blockers is the 'first dose' effect. This phenomenon describes the severe decrease in $\mathrm{BP}$, orthostatic hypotension, and syncope in patients after receiving the first dose of an $\alpha$-blocker. Other common adverse effects of $\alpha$-blockers are due to the drop in BP, such as dizziness, light-headedness, fatigue and headaches. Intraoperative 'floppy iris syndrome' (IFIS) [43] and priapism [44] are also documented adverse effects of $\alpha$-blockers and therefore patients are advised to stop the medication for up to 2 weeks prior to surgery. 


\subsubsection{Combined $\alpha / \beta$-Blockers}

A number of $\alpha / \beta$-blockers have been developed since the first, labetalol, came to clinical use in 1977. However, carvedilol is commonly used in clinical practice. Although the drugs are referred to as combined $\alpha / \beta$-blockers, their predominant mode of action is non-selective blockade of $\beta$-adrenergic receptors, with $\alpha$-adrenergic receptor blockade being a supplementary property [45]. The effects of $\beta$-blockade activate baroreceptor reflex, resulting in vasoconstriction via $\alpha$-adrenergic receptor stimulation and a consequent increase in total peripheral resistance. The additional $\alpha$-blocking properties of these classes of agents theoretically provides a greater BP-lowering effect [46]; however, studies comparing labetalol with the specific $\beta$-receptor blocker propranolol have failed to support this theory. Other studies have shown labetalol is able to lower BP without lowering cardiac output and heart rate, as opposed to propranolol, which causes significant reductions in both parameters [47, 48]. Systematic review of eight randomized, double-blind, placebo-controlled trials revealed $\alpha / \beta$-blockers lowered the trough SBP and DBP by an average of $6 \mathrm{mmHg}$ and $4 \mathrm{mmHg}$, respectively. [45] Labetalol is currently indicated for use in the management of hypertensive urgencies or emergencies [49], as well as the treatment of intraoperative and postoperative hypertension [50], and is also considered first-line in the management of hypertension in pregnancy [51]. The CAPRICORN [52] and COPERNICUS [53] trials demonstrated that carvedilol reduces mortality and morbidity in patients with chronic heart failure related to both ischemic and non-ischemic causes. It has been demonstrated that treatment with carvedilol is not only associated with more stabilized glycemic control and improved insulin resistance compared with metoprolol but also results in fewer new-onset diabetes and diabetic events in patients with heart failure [54, 55]. Analyses of studies comparing carvedilol with captopril, nifedipine or hydrochlorothiazide found that carvedilol achieved a reduction in BP similar to that achieved by its comparators [56]. $\alpha / \beta$-Blockers are generally well tolerated. Adverse effects of these agents can occur as a result of antagonism of either $\alpha$ or $\beta$ receptors. $\beta$-blocking adverse effects include dyspnoea, bronchospasm, bradycardia, malaise, and asthenia, while adverse effects due to $\alpha$-blockade include dizziness, light-headedness, fatigue and headaches. Labetolol use has also been associated with an adverse effect of a tingling scalp. Long-term use of $\alpha / \beta$ blockers can cause increased sensitivity to catecholamines due to upregulation of adrenergic receptors, and thus their abrupt withdrawal may precipitate tachyarrhythmias, acute hypertensive crises, and palpitations.

\subsection{4 a2-Adrenergic Receptor Agonists}

$\alpha$-Adrenergic receptors play a vital role in BP regulation. There are two main types of $\alpha$-adrenergic receptors $-\alpha 1$ and $\alpha 2$. $\alpha 1$ receptors are found on vascular smooth muscle, and activation leads to smooth muscle contraction, vasoconstriction and elevated BP. $\alpha 2$ receptors are found on the presynaptic neuron and activation causes negative feedback inhibition of norepinephrine release and thus a decrease in BP. Examples of $\alpha$-agonists commonly used include clonidine, guanfacine and methyldopa. The efficacy of clonidine as an antihypertensive was proved in a study in 28 patients with DBP above $110 \mathrm{mmHg}$ who had either never received pharmacological treatment or for whom previous drug therapy had not yielded a meaningful BP reduction. Following treatment with clonidine, a significant decrease in both SBP and DBP in almost all patients was observed, with an average SBP drop of $54 \mathrm{mmHg}$ and DBP drop of $22 \mathrm{mmHg}$ [57].

A Cochrane systematic review of 12 trials was conducted in 2009 comparing the effects of methyldopa with placebo. The study showed a decrease in BP by $13 / 8 \mathrm{mmHg}$ in the methyldopa group compared with the placebo group [58]. While clonidine, methyldopa and guanfacine are all approved by the US FDA for the management of hypertension, they are not recommended as a first-line therapy. In addition, methyldopa is also indicated in the management of hypertension in pregnancy. Common adverse effects of $\alpha 2$-agonists include hypotension, sedation and fatigue; $\alpha 2$ receptor agonists are contraindicated in patients with orthostatic hypotension or with any condition causing autonomic instability. Their use is also contraindicated in patients taking phosphodiesterase inhibitors.

\subsection{Vasodilators}

Vasodilators such as nitroglycerin and hydralazine are no longer mainstay treatments in hypertension but are used as an adjunct to control high BP. Vasodilators exert their action by acting at the level of the vessels by producing nitric oxide (NO), which increases cyclic guanosine monophosphate (cGMP), thus causing a relaxation in vascular smooth muscle. Nitroglycerin is primarily a venodilator and at higher doses also leads to arterial dilatation. The relaxant effect of nitroglycerin on the veins and arteries causes reduced preload and cardiac output, respectively. The main indication of nitroglycerin is angina pectoris. However, nitroglycerin is also used in special circumstances, including hypertensive emergencies associated with acute coronary syndromes or acute pulmonary oedema. Hydralazine is a direct-acting arterial vasodilator. In the Cochrane metaanalyses, it was found that after 3-6 weeks of treatment, hydralazine reduced SBP by approximately $5-20 \mathrm{mmHg}$ and DBP by $5-15 \mathrm{mmHg}$ [59]. Hydralazine has been replaced 
by other agents due to its unwanted adverse effects, including the lupus-like syndrome, which can even occur in low-dose treatment. In a longitudinal study, after 3 years of treatment, hydralazine $100 \mathrm{mg}$ /day resulted in $5.4 \%$ of patients developing lupus-like syndrome. Moreover 10.4\% developed lupus-like syndrome with hydralazine $200 \mathrm{mg} /$ day [60]. Other adverse effects include reflex tachycardia, immune-mediated hemolytic anemia, glomerulonephritis and vasculitis. However, hydralazine is still indicated in special circumstances such as pregnancy and heart failure.

\subsection{Emerging Antihypertensive Agents}

Currently available antihypertensive agents have certainly proven effective in controlling high BP; however, there is still a large proportion of patients with inadequate BP control or 'resistant hypertension'. In addition, many current treatments have some intolerable adverse effects.

Our expanding knowledge of the RAAS has led to the development of novel therapeutics, currently in both preclinical and clinical studies. Unfortunately, the coronavirus disease 2019 (COVID-19) pandemic has placed incredible strain on the conception, development and delivery of these novel drugs. Around $80 \%$ of non-COVID-19 clinical trials have been stopped or interrupted, with patient enrolments halted, laboratories closed and supply chains lost [61]. Funding and human resources have been diverted away from antihypertensive research, which will have lasting effects for patients, academic scholars and institutions.

Despite this hindrance, several drugs have shown promising safety and efficacy profiles in preclinical trials and are now in phase II/III testing (Table 2). These have a variety of mechanisms, targeting newly elucidated pathways implicated in the pathophysiology of hypertension. There are also other promising candidates that are still in the preclinical stages, including insulin-resistant aminopeptidase (IRAP), endothelin receptor antagonists (ERAs), dual-acting bispecific peptides and soluble guanylyl cyclase A (sGC) stimulators.

\subsubsection{Non-Steroidal Mineralocorticoid Receptor Antagonists}

A frequent adverse effect of steroid mineralocorticoid receptor (MR) antagonists, such as spironolactone, is hyperkalemia. One interesting feature of the MRs is that they have essentially equivalent affinity for a range of other steroids, including progesterone, cortisol and corticosterone, at a level equivalent to that of aldosterone [62]. Novel non-steroidal selective MR blockers have been developed and esaxerenone was licensed for the treatment of hypertension in Japan in 2019 [63]. In one in vitro study using pituitary GH3 cells, esaxerenone inhibited the transient, late and persistent components of the voltage-gated $\mathrm{Na}^{+}$current in a concentration-, time-, state- and hysteresis-dependent manner [64]. This was shown to be independent and upstream of its action on the MR and further in vivo studies are in progress to assess its benefit in related conditions, such as primary hyperaldosteronism, CKD and refractory hypertension $[65,66]$.

\subsubsection{Aminopeptidase Inhibitors}

Aminopeptidase (APA) is an enzyme that cleaves the $\mathrm{N}$-terminal aspartate reside from AT II, converting it to AT III (and AT IV) in the brain. Here, AT III contributes to the regulation of $\mathrm{BP}$ through three $\mathrm{AT}_{1}$ receptor-phospholipase C (PLC)-dependent pathways-sympathetic nerve activation and subsequent noradrenaline release, inhibition of the baroreflex in the nucleus of the tractus solitarius, and stimulation of vasopressin release [67]. As such, there is interest in selective inhibitors of brain APA, such as the prodrug firibastat, which crosses the blood-brain barrier, and the active products that inhibit brain APA activity [68].

\subsubsection{Natriuretic Peptide}

Not only does the heart pump blood but it also secretes cardiac natriuretic peptides (NPs), which play a crucial role in maintaining cardiovascular homeostasis and regulating BP and glucose and lipid metabolism. These NPs are released in response to atrial or ventricular muscular wall stress from increased intravascular pressure and/or transmural pressure (e.g. due to heart failure, MI or cardiomyopathies) [69]. One of these NPs is B-type NP (BNP), which interacts with membrane-bound guanylyl cyclase A to activate protein kinase $\mathrm{G}$ via cGMP. The downstream effects include vasodilation and natriuretic and diuretic effects, which all contribute to lowering BP. [70]

Although ANP deficiency causes hypertension (and its overexpression hypotension), ANP levels are elevated in essential hypertension. However, this represents a protective and compensatory response to cardiac wall stress and the increased ANP may also attenuate the upregulation of renin synthesis, therefore buffering renin-dependent hypertension $[71,72]$. The serine protease Corin was identified as the enzyme responsible for converting pro-ANP to active ANP. Its importance in regulating BP is currently being evaluated, especially in managing pregnancy-induced hypertension [73].Neprilysin is a membrane-bound zinc endopeptidase present in various organs that breaks down BNP. As such, there is interest in using neprilysin inhibitors (NEPi) to prevent its degradation and extend its beneficial effects on lowering BP [74]. Dual inhibition of AT II receptor and neprilysin (ARNI) led to a greater BP reduction compared with blocking the AT II receptor alone [75]. NEPi such as sacubitril in combination with valsartan have been approved for the use of both heart failure with reduced ejection 


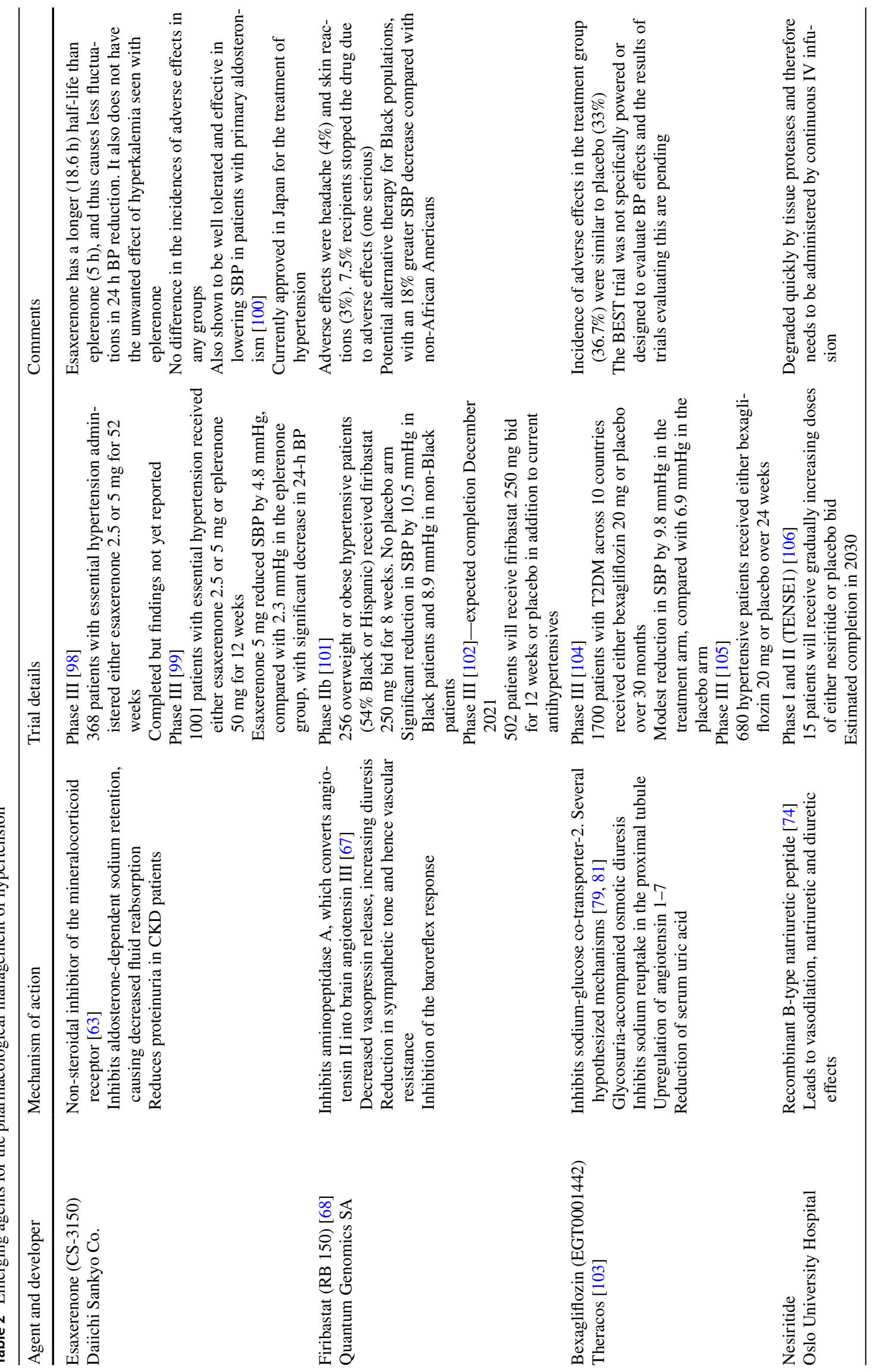


fraction (HFrEF) and heart failure with preserved ejection fraction (HFpEF) [76]. Recently, Chua et al. [77] conducted a systematic review of RCTs comprising 5931 patients. The group reported that when compared with placebo, sacubitril/ valsartan provided a mean reduction of SBP and DBP by $6.52 \mathrm{mmHg}$ and $3.32 \mathrm{mmHg}$, respectively. Despite sacubitril/valsartan being effective and well tolerated in patients with hypertension, the drug is not currently approved for use in this indication.

\subsubsection{Sodium Glucose Co-Transporter 2 Inhibitors}

Sodium glucose co-transporter 2 inhibitors block glucose reabsorption in the renal proximal tubule, increasing urinary glucose excretion, and are primarily prescribed for the management of type 2 diabetes mellitus (T2DM); however, several studies have demonstrated the cardiovascular benefits of SGLT2 inhibitors [78]. The glycosuria-accompanied osmotic diuresis increases urine output and may therefore decrease intravascular volume [79]. In addition, SGLT2 inhibitors may inhibit the $\mathrm{Na}^{+} / \mathrm{H}^{+}$ exchanging channel isoform 3 , increasing $\mathrm{Na}^{+}$excretion and reducing preload. Their mechanism of action has been shown to be independent of GFR, suggesting that factors independent of volume depletion also contribute, including upregulation of AT 1-7, decreased arterial stiffness and reductions in serum uric acid [80]. The SGLT2 inhibitor dapagliflozin has also been shown to significantly improve the peripheral microvascular endothelial function leading to reduced BP. This mechanism is postulated to be through a reduction in the oxidative stress, improving the functional recovery of impaired microcirculation and abnormal vasomotion of arterioles with increased vascular tone [81]. With a considerable overlap of patient populations with T2DM and hypertension, interest is growing in the antihypertensive effects of SGLT2 inhibitors.

\subsubsection{Soluble Guanylate Cyclase Stimulators}

Soluble guanylate cyclase (sGC) is the primary target of $\mathrm{NO}$ in the cardiovascular system, eliciting many of the biological actions of NO via cGMP [82]. The NO/sGC/cGMP pathway is involved in the regulation of vasodilation and our understanding of its role in hypertension is evolving. Stimulators of sGC replace the oxidised hem cofactor, the loss of which causes sGC to become NO-insensitive [83]. sGC stimulators have been shown to ameliorate pulmonary and portal hypertension through stopping transforming growth factor (TGF)- $\beta$ /connective tissue growth factor (CTGF) upregulation and subsequent hepatic stellate cell activation [84]. Other sGC stimulators effectively inhibited leukocyte recruitment and the adhesive properties of neutrophils to fibronectin in sickle cell mice. These agents significantly reduced the frequency of vaso-occlusive episodes, complementing their established dose-dependent 
blood pressure-lowering effects [85]. Olinciguat, another sGC stimulator that is currently in phase II clinical development for use in patients with sickle cell anemia, not only reduces $\mathrm{BP}$ in humans and in hypertensive and normotensive rats but also successfully reduces inflammatory mechanisms in TNF-stimulated mice. [86]

\subsubsection{Endothelin Receptor Antagonists}

The endothelin axis is involved in the physiological regulation of vascular tone through the $G$ protein-coupled receptors $\mathrm{ET}_{\mathrm{A}}$ and $\mathrm{ET}_{\mathrm{B}}$, and overproduction of endothelin has been implicated in the pathology of pulmonary arterial hypertension [87]. Trials with ERAs have shown BP reduction in models of salt-sensitive hypertension and patients with resistant hypertension $[88,89]$. The SONAR trial also supported a potential role of ERAs in protecting renal function in patients with T2DM at high risk of developing end-stage kidney disease [90]. Furthermore, in vitro placental studies have shown direct transfer of ERAs across human placenta at term, and that the $\mathrm{ET}_{\mathrm{A}}$ receptor mediates endothelin-induced constriction in the fetoplacental vasculature, suggesting a role for ERAs in preventing pre-eclampsia [89]. Several large clinical trials have been completed to explore their potential use in treatment-resistant hypertension.

The first major investigation was the DORADO trial, where 379 patients with resistant hypertension treated with darusentan had an absolute reduction in BP compared with placebo, with only fluid accumulation as main adverse side effect [89]. However, the larger DORADO-AC trial, which included an active control agent (guanfacine), showed no significant BP difference between darusentan and placebo after 14 weeks of treatment [88]. Consequently, the manufacturer put further development of this agent on hold in treatment-resistant hypertension. More recently, aprocitentan is currently under investigation in the PRECISION phase III trial in 1971 patients with resistant hypertension [91, 92]. Previous studies have shown promising results; aprocitentan significantly reduced BP compared with placebo and lisinipril [93] and was shown to potentiate the antihypertensive effect of RAS blockers, suggesting a role in combination therapy [94]. The results of the PRECISION trial are estimated to be published in mid-2022. Bosentan is approved for the treatment of PAH and is currently in clinical trials studying its pharmacodynamics, and a further phase II trial in patients with hypertension is expected to be complete in November 2022 [95, 96].

\subsection{Management of Hypertension in Specific Population Subgroups}

Hypertension is a complex, multifactorial disorder that often exists with other comorbidities. Consequently, managing hypertension in specific groups of patients requires different strategies and combinations of pharmacological agents. Some of these populations yet to be discussed include patients with CKD, diabetes mellitus or obesity.

The majority (67-92\%) of patients with CKD have comorbid hypertension [112]. The JNC-8 recommends a BP goal of $<140 / 90 \mathrm{mmHg}$ [7], while the Kidney Disease Improving Global Outcomes (KDIGO) BP work group, which analysed systematic reviews and meta-analyses, suggested considering a lower target of $<130 / 80 \mathrm{mmHg}$ in patients with CKD and albuminuria $>300 \mathrm{mg} /$ day or a urine albumin-to-creatinine ratio of $>30 \mathrm{mg} / \mathrm{g}$ [113]. The ACC/ AHA guidelines advocate in favour of the Systolic Blood Pressure Intervention Trial (SPRINT) results and therefore recommend a BP goal of $>130 / 80 \mathrm{mmHg}$ for all patients with CKD [4]. ACEi (or ARBs if ACEi are not tolerated) are recommended as the first-line agents for the management of hypertension in patients with CKD stage 3 or higher, or stage 1 or 2 with albuminuria $>300 \mathrm{mg} /$ day. As ACEi/ARBs reduce albuminuria through reduction of intra-glomerular pressure leading to a decrease in GFR, serum creatinine may rise up to $30 \%$ from baseline; however, a higher rise should warrant further investigation for acute renal failure [114]. Due to the risk of hyperkalemia and acute kidney injury, combination of an ACEi/ARB or ACEi/ARB with aliskiren should be avoided. If BP still remains poorly controlled then diuretics may be a rational option, especially in settings of volume overload, and non-dihydropyridine CCBs could be considered for patients with persistent proteinuria $[115,116]$. A number of epidemiologic studies have demonstrated a 1.5- to 2-fold greater prevalence of hypertension in patients with diabetes mellitus when compared with non-diabetic patients [117]. When pharmacologic therapy becomes necessary for the management of high BP, clinical practice guidelines published jointly by the AHA, ACC and a number of other organizations suggest diuretics, CCBs, ACEi and ARBs [4]. The ALLHAT study found that ACEi provided a bigger reduction in mean fasting glucose levels (change in mean fasting glucose level for the diuretic, CCB and ACEi groups were $+2.8 \mathrm{mg} / \mathrm{dL},+0.6 \mathrm{mg} / \mathrm{dL}$ and $-1.4 \mathrm{mg} / \mathrm{dL}$, respectively) $[18,118]$. Consequently, ACEi have become the initial mainstay choice for managing hypertension in diabetic patients struggling with glycemic control. Moreover, meta-analysis of controlled trials comparing antihypertensives in diabetic patients with kidney disease revealed a lower incidence of end-stage renal disease with the use of ACEi and ARBs, and therefore recommended these agents for managing hypertension in patients with diabetes and albuminuria [119]. In both obese and morbidly obese patients, pharmacological treatment requires a flexible approach given the metabolic and hemodynamic abnormalities present in this group. Causes of hypertension are multifactorial but include chronic insulin resistance, impaired 
renal pressure natriuresis and extracellular fluid volume expansion [120]. RAAS blockers, such as ACEi or ARBs are considered first-line, although monotherapy is seldom sufficient to control BP. Often, thiazide diuretics and BBs are combined with RAAS inhibitors; however, given their metabolic adverse effects [121], dihydropyridine CCBs may be more beneficial as they are metabolically neutral [122]. The excess adipose tissue in these patients also secretes aldosterone-releasing factors, stimulating aldosterone secretion and causing MR activation [123]. This hyperaldosteronism causes salt-sensitive hypertension independent of the systemic RAAS. Findings by Buglioni et al. [124] and Morales et al. [125] indicate a significant decrease in plasma aldosterone levels and mean BP in obese patients taking mineralocorticoid receptor antagonists (MRA) versus with RAAS blockers, suggesting combination therapy with MRA may improve BP control.

\section{Conclusion}

Over the last four decades, there has been significant progress in developing pharmacological agents to control hypertension via various mechanisms and pathways. Despite these advancements, heart disease remains the number one cause of mortality worldwide, a large proportion of which can be attributed to poorly controlled BP. Several novel pathways have been targeted in order to lower BP. However, given the severe acute respiratory syndrome coronavirus 2 (SARS$\mathrm{CoV}-2$ ) pandemic, progress in developing these agents has been slow. Nevertheless, with many of these agents in phase III clinical trials, the data emerging from recent studies has been encouraging and could hold promise in adequately controlling BP. Indeed, further trials must then establish which combination of current and novel agents provide not only the most therapeutic value but also pose the greatest risks of adverse effects.

Acknowledgements Images were created and adapted from Smart Servier Medical Art (https://smart.servier.com/).

\section{Declarations}

Funding This research received no specific grant from any funding agency in the public, commercial or not-for-profit sectors.

Conflict of interests Utkarsh Ojha, Sanjay Ruddaraju, Navukkarasu Sabapathy, Varun Ravindran, Pitchaya Worapongsatitaya, Jeesanul Haq, Raihan Mohammed and Vinod Patel have no conflicts of interest to declare.

Ethical approval Not applicable.

Consent to participate Not applicable.
Consent for publication Not applicable.

Availability of data and materials Not applicable.

Code availability Not applicable.

Author contributions UO, SR, NS, RM, PW, VR and JH were involved in the literature review, interpretation of data, and drafting and editing of the manuscript. Vinod Patel was involved in the conception, revision and supervision of the manuscript. All authors approved the final manuscript and agree to be accountable for all aspects.

\section{References}

1. Chobanian AV, Bakris GL, Black HR, for the National Heart, Lung, and Blood Institute, et al. Report of the Joint National Committee on Prevention, Detection, Evaluation, and Treatment of High Blood Pressure. Hypertension. 2003;42:1206-52.

2. Alcocer L, Cueto L. Hypertension, a health economics perspective. Ther Adv Cardiovasc Dis. 2008;2:147-55.

3. Psaty BM, Lumley T, Furberg CD, et al. Health outcomes associated with various antihypertensive therapies used as first-line agents: a network meta-analysis. JAMA. 2003;289:2534-44.

4. Whelton P, Carey R, Aronow W, Casey D, Collins K, Dennison Himmelfarb C, et al. 2017 ACC/AHA/AAPA/ABC/ACPM/AGS/ APhA/ASH/ASPC/NMA/PCNA Guideline for the Prevention, Detection, Evaluation, and Management of High Blood Pressure in Adults. J Am Coll Cardiol. 2018;71(19):e127-248.

5. Unger T, Borghi C, Charchar F, Khan NA, Poulter NR, Prabhakaran D, et al. 2020 International Society of Hypertension Global Hypertension Practice Guidelines. Hypertension. 2020;75(6):1334-57.

6. Aurell M, Rudin A, Tisell LE, Kindblom LG, Sandberg G. Captopril effect on hypertension in patient with renin-producing tumour. Lancet. 1979;2(8134):149-50.

7. James PA, Oparil S, Carter BL, et al. 2014 Evidence-Based guideline for the management of high blood pressure in adults: report From the Panel Members Appointed to the Eighth Joint National Committee (JNC 8). JAMA. 2014;311(5):507-20.

8. Gavras H, Gavras I. Angiotensin converting enzyme inhibitors. Properties and side effects. Hypertension. 1988;11(3 Pt 2):II37-41

9. Israili $\mathrm{ZH}$. Clinical pharmacokinetics of angiotensin II (AT 1) receptor blockers in hypertension. J Hum Hypertens. 2000;14(Suppl 1):S73.

10 Heran BS, Wong MM, Heran IK, Wright JM. Blood pressure lowering efficacy of angiotensin receptor blockers for primary hypertension. Cochrane Database Syst Rev. 2008;4:CD003822.

11. Matchar DB, McCrory DC, Orlando LA, Patel MR, Patel UD, Patwardhan MB, et al. Systematic review: comparative effectiveness of angiotensin-converting enzyme inhibitors and angiotensin II receptor blockers for treating essential hypertension. Ann Intern Med. 2008;148(1):16-29.

12. Rodgers JE, Patterson JH. Angiotensin II-receptor blockers: clinical relevance and therapeutic role. Am J Health Syst Pharm. 2001;58(8):671-83.

13. Johansen TL, Kjaer A. Reversible renal impairment induced by treatment with the angiotensin II receptor antagonist candesartan in a patient with bilateral renal artery stenosis. BMC Nephrol. 2001;2:1.

14. Kaufman MB. ACE inhibitor-related angioedema: are your patients at risk. P T. 2013;38(3):170-2. 
15. Jensen $C$, Herold $P$, Brunner HR. Aliskiren: the first renin inhibitor for clinical treatment. Nat Rev Drug Discov. 2008;7(5):399.

16. Staessen JA, Li Y, Richart T. Oral renin inhibitors. The Lancet. 2006;368(9545):1449-56.

17. Musini VM, Lawrence KAK, Fortin PM, Bassett K, Wright JM. Blood pressure lowering efficacy of renin inhibitors for primary hypertension. Cochrane Database Syst Rev. 2017;4:CD007066.

18. ALLHAT Officers and Coordinators for the ALLHAT Collaborative Research Group. The Antihypertensive and Lipid-Lowering Treatment to Prevent Heart Attack Trial. Major outcomes in high-risk hypertensive patients randomized to angiotensin-converting enzyme inhibitor or calcium channel blocker vs diuretic: The Antihypertensive and Lipid-Lowering Treatment to Prevent Heart Attack Trial (ALLHAT). JAMA. 2002;288(23):2981-97.

19. Julius S, Kjeldsen SE, Weber M, Brunner HR, Ekman S, Hansson $\mathrm{L}$, et al. Outcomes in hypertensive patients at high cardiovascular risk treated with regimens based on valsartan or amlodipine: the VALUE randomised trial. Lancet. 2004;363(9426):2022-31.

20. Laurent S. Antihypertensive drugs. Pharmacol Res. 2017;124:116-25.

21. Dougall HT, McLay J. A comparative review of the adverse effects of calcium antagonists. Drug Saf. 1996;15(2):91-106.

22. Elliott WJ, Ram CV. Calcium channel blockers. J Clin Hypertens (Greenwich). 2011;13(9):687-9.

23 Musini VM, Nazer M, Bassett K, Wright JM. Blood pressure-lowering efficacy of monotherapy with thiazide diuretics for primary hypertension. Cochrane Database Syst Rev. 2014;5:CD003824.

24. Roush GC, Kaur R, Ernst ME. Diuretics: a review and update. J Cardiovasc Pharmacol Ther. 2014;19(1):5-13.

25. Dahlöf B, Lindholm LH, Hanson L, Scherstén B, Ekbom T, Wester PO. Morbidity and mortality in the Swedish Trial in Old Patients With Hypertension (STOP-Hypertension). Lancet. 1991;338:1281-5.

26. Eriksson S, Olofsson BO, Wester PO. Atenolol in the secondary prevention after stroke. Cerebrovasc Dis. 1995;5:21-5.

27. Dahlöf B, Devereux R, Kjeldsen S, Julius S, Beevers G, de Faire U, et al. Cardiovascular morbidity and mortality in the Losartan Intervention For Endpoint reduction in hypertension study (LIFE): a randomised trial against atenolol. The Lancet. 2002;359(9311):995-1003

28. Dahlöf B, Sever P, Poulter N, Wedel H, Beevers D, Caulfield $\mathrm{M}$, et al. Prevention of cardiovascular events with an antihypertensive regimen of amlodipine adding perindopril as required versus atenolol adding bendroflumethiazide as required, in the Anglo-Scandinavian Cardiac Outcomes Trial-Blood Pressure Lowering Arm (ASCOT-BPLA): a multicentre randomised controlled trial. The Lancet. 2005;366(9489):895-906.

29. Khan N. Re-examining the efficacy of beta-blockers for the treatment of hypertension: a meta-analysis. Can Med Assoc J. 2006;174(12):1737-42.

30. Williams B, Lacy PS, Thom SM, Cruickshank K, Stanton A, Collier D, CAFE Investigators; Anglo-Scandinavian Cardiac Outcomes Trial Investigators; CAFE Steering Committee and Writing Committee, et al. Differential impact of blood pressure-lowering drugs on central aortic pressure and clinical outcomes: principal results of the Conduit Artery Function Evaluation (CAFE) study. Circulation. 2006;113(9):1213-25.

31. Ciulla MM, Paliotti R, Esposito A, Dìez J, López B, Dahlöf B, et al. Different effects of antihypertensive therapies based on losartan or atenolol on ultrasound and biochemical markers of myocardial fibrosis: results of a randomized trial. Circulation. 2004;110(5):552-7.

32. Lithell HO. Effect of antihypertensive drugs on insulin, glucose, and lipid metabolism. Diabetes Care. 1991;14(3):203-9.
33 Wright JM, Musini VM. First-line drugs for hypertension. Cochrane Database Syst Rev. 2009;3:CD001841.

34. Ripley T, Saseen J. $\beta$-Blockers. Ann Pharmacother. 2014;48(6):723-33.

35. Elliott W, Childers W. Should $\beta$ blockers no longer be considered first-line therapy for the treatment of essential hypertension without comorbidities? Curr Cardiol Rep. 2011;13(6):507-16.

36. Messerli F, Bell D, Fonseca V, Katholi R, McGill J, Phillips $\mathrm{R}$, et al. Body weight changes with $\beta$-blocker use: results from GEMINI. Am J Med. 2007;120(7):610-5.

37. Heran BS, Galm BP, Wright JM. Blood pressure lowering efficacy of alpha blockers for primary hypertension. Cochrane Database Syst Rev. 2012;8:CD004643.

38. Vidt DG. Alpha-blockers and congestive heart failure: early termination of an arm of the ALLHAT trial. Cleve Clin J Med. 2000;67(6):429-33.

39. McConnell JD, Roehrborn CG, Bautista OM, et al. The longterm effect of doxazosin, finasteride, and combination therapy on the clinical progression of benign prostatic hyperplasia. $\mathrm{N}$ Engl J Med. 2003;349(25):2387-98.

40 Roehrborn CG, Siami P, Barkin J, Damião R, Major-Walker K, Nandy I, CombAT Study Group, et al. The effects of combination therapy with dutasteride and tamsulosin on clinical outcomes in men with symptomatic benign prostatic hyperplasia: 4-year results from the CombAT study. Eur Urol. 2010;57(1):123-31.

41 Tuncel M, Ram VC. Hypertensive emergencies. Etiology and management. Am J Cardiovasc Drugs. 2003;3(1):21-31.

42. Garg MK, Kharb S, Brar KS, Gundgurthi A, Mittal R. Medical management of pheochromocytoma: Role of the endocrinologist. Indian J Endocrinol Metab. 2011;15 Suppl 4(Suppl4):S329-36.

43. Zaman F, Bach C, Junaid I, Papatsoris AG, Pati J, Masood J, et al. The floppy iris syndrome - what urologists and ophthalmologists need to know. Curr Urol. 2012;6(1):1-7.

44. Prihadi JC, Kusumajaya C. Priapism secondary to tamsulosin: a case report. Int J Surg Case Rep. 2020;72:460-3.

45. Wong GW, Laugerotte A, Wright JM. Blood pressure lowering efficacy of dual alpha and beta blockers for primary hypertension. Cochrane Database Syst Rev. 2015;8:CD007449.

46. Mann SJ. Combined $\alpha / \beta$ blockade: An underused approach to the treatment of resistant hypertension. J Clin Hypertens (Greenwich). 2007;9(9):663-6.

47. Prichard BNC, Richards DA. Comparison of Labetalol with other antihypertensive drugs. Br J Clin Pharmacol. 1982;13(Suppl 1):41S-47S.

48. Cohn JN, Mehta J, Francis GS. A review of the haemodynamic effects of labetalol in man. Br J Clin Pharmacol. 1982;13(1 Suppl):19S-26S.

49 Vidt DG. Emergency room management of hypertensive urgencies and emergencies. J Clin Hypertens (Greenwich). 2001;3(3):158-64.

50. Muzzi DA, Black S, Losasso TJ, Cucchiara RF. Labetalol and esmolol in the control of hypertension after intracranial surgery. Anesth Analg. 1990;70(1):68-71.

51. Brown CM, Garovic VD. Drug treatment of hypertension in pregnancy. Drugs. 2014;74(3):283-96.

52. Dargie HJ. Effect of carvedilol on outcome after myocardial infarction in patients with left-ventricular dysfunction: the CAPRICORN randomised trial. Lancet. 2001;357(9266):1385-90.

53. Packer M, Fowler MB, Roecker EB, Coat AJ, Katus HA, Krum $\mathrm{H}$, et al. Effect of carvedilol on the morbidity of patients with severe chronic heart failure: results of the carvedilol prospective randomized cumulative survival (COPERNICUS) study. Circulation. 2002;106(17):2194-9. 
54. Bakris GL, Fonseca V, Katholi RE, McGill JB, Messerli FH, Phillips RA, et al. Metabolic effects of carvedilol vs metoprolol in patients with type 2 diabetes mellitus and hypertension: a randomized controlled trial. JAMA. 2004;292(18):2227-36.

55. Torp-Pedersen C, Metra M, Charlesworth A, Spark P, Lukas MA, Poole-Wilson PA. Effects of metoprolol and carvedilol on preexisting and new onset diabetes in patients with chronic heart failure: data from the Carvedilol Or Metoprolol European Trial (COMET). Heart. 2007;93(8):968-73.

56. Moser M, Frishman W. Results of therapy with carvedilol, a betablocker vasodilator with antioxidant properties, in hypertensive patients. Am J Hypertens. 1998;11(1 Pt 2):15S-22S.

57. MacDougall AI, Addis GJ, MacKay N, et al. Treatment of hypertension with clonidine. BMJ. 1970;3(5720):440-2. https://doi. org/10.1136/bmj.3.5720.440.

58 Mah GT, Tejani AM, Musini VM. Methyldopa for primary hypertension. Cochrane Database Syst Rev. 2009;4:CD003893.

59 Kandler MR, Mah GT, Tejani AM, Stabler SN, Salzwedel DM. Hydralazine for essential hypertension. Cochrane Database Syst Rev. 2011;11:CD004934.

60. Cameron HA, Ramsay LE. The lupus syndrome induced by hydralazine: a common complication with low dose treatment. Br Med J (Clin Res Ed). 1984;289(6442):410-2. https://doi.org/ 10.1136/bmj.289.6442.410.

61. van Dorn A. COVID-19 and readjusting clinical trials. Lancet. 2020;396(10250):523-4.

62. Funder JW. Mineralocorticoid receptor antagonists: emerging roles in cardiovascular medicine. Integr Blood Press Control. 2013;6:129-38

63. Ito S, Itoh H, Rakugi H, Okuda Y, Yamakawa S. Efficacy and safety of esaxerenone (CS-3150) for the treatment of essential hypertension: a phase 2 randomized, placebo-controlled, doubleblind study. J Hum Hypertens. 2019;33(7):542-51.

64. Chang WT, Wu SN. Characterization of direct perturbations on voltage-gated sodium current by esaxerenone, a nonsteroidal mineralocorticoid receptor blocker. Biomedicines. 2021;9(5):549.

65. Rakugi H, Ito S, Itoh H, Okuda Y, Yamakawa S. Long-term phase 3 study of esaxerenone as mono or combination therapy with other antihypertensive drugs in patients with essential hypertension. Hypertens Res. 2019;42(12):1932-41.

66. Capelli I, Gasperoni L, Ruggeri M, Donati G, Baraldi O, Sorrenti $\mathrm{G}$, et al. New mineralocorticoid receptor antagonists: update on their use in chronic kidney disease and heart failure. J Nephrol. 2020;33(1):37-48.

67. Llorens-Cortes C, Touyz RM. Evolution of a new class of antihypertensive drugs: targeting the brain renin-angiotensin system. Hypertension. 2020;75(1):6-15.

68. Fournie-Zaluski MC, Fassot C, Valentin B, Djordjijevic D, Reaux-Le Goazigo A, Corvol P, et al. Brain renin-angiotensin system blockade by systemically active aminopeptidase A inhibitors: a potential treatment of salt-dependent hypertension. Proc Natl Acad Sci USA. 2004;101(20):7775-80.

69. Wang TJ, Larson MG, Levy D, Benjamin EJ, Leip EP, Omland $\mathrm{T}$, et al. Plasma natriuretic peptide levels and the risk of cardiovascular events and death. N Engl J Med. 2004;350(7):655-63.

70. Kato Y, Mori K, Kasahara M, et al. Natriuretic peptide receptor guanylyl cyclase-A pathway counteracts glomerular injury evoked by aldosterone through p38 mitogen-activated protein kinase inhibition. Sci Rep. 2017;7:46624.

71. Yasumoto K, Takata M, Ueno H, Tomita S, Tomoda F, Inoue H. Relation of plasma brain and atrial natriuretic peptides to left ventricular geometric patterns in essential hypertension. Am J Hypertens. 1999;12(9 Pt 1):921-4.
72. Demerath T, Staffel J, Schreiber A, Valletta D, Schweda F. Natriuretic peptides buffer renin-dependent hypertension. Am J Physiol Renal Physiol. 2014;306(12):F1489-98.

73. Zhou Y, Jiang J, Cui Y, Wu Q. Corin, atrial natriuretic peptide and hypertension. Nephrol Dial Transplant. 2009;24(4):1071-3.

74. Campbell DJ. Long-term neprilysin inhibition-implications for ARNIs. Nat Rev Cardiol. 2017;14(3):171-86.

75. Ruilope LM, Dukat A, Böhm M, Lacourcière Y, Gong J, Lefkowitz MP. Blood-pressure reduction with LCZ696, a novel dualacting inhibitor of the angiotensin II receptor and neprilysin: a randomised, double-blind, placebo-controlled, active comparator study. Lancet. 2010;375(9722):1255-66.

76. Pericas P, Mas-Lladó C, Ramis-Barceló MF, Valadrón I, Noris Mora M, Pasamar Márquez L, et al. Impact of sacubitril-valsartan treatment on diastolic function in patients with heart failure and reduced ejection fraction. High Blood Press Cardiovasc Prev. 2021;28(2):167-75.

77. Chua SK, Lai WT, Chen LC, Hung HF. The Antihypertensive effects and safety of LCZ696 in patients with hypertension: a systemic review and meta-analysis of randomized controlled trials. J Clin Med. 2021;10(13):2824.

78. van Bommel EJ, Muskiet MH, Tonneijck L, Kramer MH, Nieuwdorp M, van Raalte DH. SGLT2 inhibition in the diabetic kidney-from mechanisms to clinical outcome. Clin J Am Soc Nephrol. 2017;12(4):700-10.

79 Ojha U, Reyes L, Eyenga F, Oumbe D, Watkowska J, SaintJacques H. Diabetes, heart failure and beyond: elucidating the cardioprotective mechanisms of sodium glucose cotransporter 2 (SGLT2) inhibitors. Am J Cardiovasc Drugs. 2021. https://doi. org/10.1007/s40256-021-00486-6 (Epub 30 Jun 2021).

80. Yale JF, Bakris G, Cariou B, Yue D, David-Neto E, Xi L, et al. Efficacy and safety of canagliflozin in subjects with type 2 diabetes and chronic kidney disease. Diabetes Obes Metab. 2013;15(5):463-73.

81. Varzideh F, Kansakar U, Santulli G. SGLT2 inhibitors in cardiovascular medicine. Eur Heart J Cardiovasc Pharmacother. 2021;7(4):e67-8.

82. Sips PY, Buys ES. Genetic modification of hypertension by sGC $\alpha 1$. Trends Cardiovasc Med. 2013;23(8):312-8.

83. Buys E, Sips P. New insights into the role of soluble guanylate cyclase in blood pressure regulation. Curr Opin Nephrol Hypertens. 2014;23(2):135-42.

84. Chen PJ, Kuo LM, Wu YH, Chang YC, Lai KH, Hwang TL. BAY 41-2272 attenuates CTGF expression via sGC/cGMPindependent pathway in TGF $\beta 1$-activated hepatic stellate cells. Biomedicines. 2020;8(9):330.

85. Ferreira WA Jr, Chweih H, Lanaro C, et al. Beneficial effects of soluble guanylyl cyclase stimulation and activation in sickle cell disease are amplified by hydroxyurea: in vitro and in vivo studies. J Pharmacol Exp Ther. 2020;374(3):469-78.

86. Zimmer DP, Shea CM, Tobin JV, Tchernychev B, Germano $\mathrm{P}$, Sykes K, et al. Olinciguat, an oral sGC stimulator, exhibits diverse pharmacology across preclinical models of cardiovascular, metabolic, renal, and inflammatory disease. Front Pharmacol. 2020;11:419.

87. Enevoldsen FC, Sahana J, Wehland M, Grimm D, Infanger M, Krüger M. Endothelin receptor antagonists: status quo and future perspectives for targeted therapy. J Clin Med. 2020;9(3):824.

88. Bakris GL, Lindholm LH, Black HR, Krum H, Linas S, Linseman JV, et al. Divergent results using clinic and ambulatory blood pressures: report of a darusentan-resistant hypertension trial. Hypertension. 2010;56(5):824-30.

89. Weber MA, Black H, Bakris G, Krum H, Linas S, Weiss R, et al. A selective endothelin-receptor antagonist to reduce blood pressure in patients with treatment-resistant hypertension: a 
randomised, double-blind, placebo-controlled trial. Lancet. 2009;374(9699):1423-31.

90. Heerspink HJL, Parving HH, Andress DL, Bakris G, CorreaRotter R, Hou FF, SONAR Committees and Investigators, et al. Atrasentan and renal events in patients with type 2 diabetes and chronic kidney disease (SONAR): a double-blind, randomised, placebo-controlled trial. Lancet. 2019;393(10184):1937-47.

91. A Research Study to Show the Effect of Aprocitentan in the Treatment of Difficult to Control (Resistant) High Blood Pressure (Hypertension) and Find Out More About Its Safety (PRECISION). ClinicalTrials.gov [cited 24 Oct 2021]. https://clinicaltr ials.gov/ct2/show/NCT03541174.

92. Angeli F, Verdecchia P, Reboldi G. Aprocitentan, a dual endothelin receptor antagonist under development for the treatment of resistant hypertension. Cardiol Ther. 2021;10(2):397-406.

93. Verweij P, Danaietash P, Flamion B, Ménard J, Bellet M. Randomized dose-response study of the new dual endothelin receptor antagonist aprocitentan in hypertension. Hypertension. 2020;75(4):956-65.

94. Trensz F, Bortolamiol C, Kramberg M, Wanner D, Hadana H, Rey M, et al. pharmacological characterization of aprocitentan, a dual endothelin receptor antagonist, alone and in combination with blockers of the renin angiotensin system, in two models of experimental hypertension. J Pharmacol Exp Ther. 2019;368(3):462-73.

95. Endothelin Receptor Function and Acute Stress-Full Text ViewClinicalTrials.Gov [Internet]. Clinicaltrials.gov. [cited 2021 Oct 24]. https://clinicaltrials.gov/ct2/show/NCT02116335.

96. Vascular and renal impact of endothelin-1 receptor blockade in patients with resistant arterial hypertension. ClinicalTrials.gov [cited 24 Oct 2021]. https://clinicaltrials.gov/ct2/show/NCT04 388124.

97. Hitzerd E, Neuman RI, Broekhuizen M, Simons SHP, Schoenmakers S, Reiss IKM, et al. Transfer and vascular effect of endothelin receptor antagonists in the human placenta. Hypertension. 2020;75(3):877-84.

98. Long-term Study of CS-3150 as Monotherapy or in Combination With Other Antihypertensive Drug in Japanese Patients With Essential Hypertension. ClinicalTrials.gov. [cited 21 Jun 2021]. https://clinicaltrials.gov/ct2/show/NCT02722265.

99. Study of CS-3150 in Patients With Essential Hypertension. ClinicalTrials.gov [cited 21 Jun 2021]. https://clinicaltrials.gov/ct2/ show/NCT02890173.

100. Satoh $\mathrm{F}$, Ito $\mathrm{S}$, Itoh $\mathrm{H}$, Rakugi $\mathrm{H}$, Shibata $\mathrm{H}$, Ichihara A, Omura M, Takahashi K, Okuda Y, Iijima S. Efficacy and safety of esaxerenone (CS-3150), a newly available nonsteroidal mineralocorticoid receptor blocker, in hypertensive patients with primary aldosteronism. Hypertens Res. 2021;44(4):464-72.

101. Novel Evaluation With QGC001 in Hypertensive Overweight Patients of Multiple Ethnic Origins (NEW-HOPE). ClinicalTrials.gov. 2021 [cited 21 Jun 2021]. https://clinicaltrials.gov/ct2/ show/NCT03198793.

102. Firibastat in Treatment-resistant Hypertension (FRESH). ClinicalTrials.gov. 2021 [cited 21 Jun 2021]. https://clinicaltrials.gov/ ct2/show/NCT04277884.

103. Allegretti AS, Zhang W, Zhou W, Thurber TK, Rigby SP, Bowman-Stroud C, et al. Safety and effectiveness of bexagliflozin in patients with type 2 diabetes mellitus and stage 3a/3b CKD. Am J Kidney Dis. 2019;74(3):328-37.

104. Bexagliflozin Efficacy and Safety Trial (BEST) (BEST). ClinicalTrials.gov. 2021 [cited 21 Jun 2021]. https://clinicaltrials.gov/ ct2/show/NCT02558296.

105. An Integrated Assessment of the Safety and Effectiveness of Bexagliflozin for the Management of Essential Hypertension. ClinicalTrials.gov. 2021 [cited 21 Jun 2021]. https://clinicaltr ials.gov/ct2/show/NCT03514641.
106. Nesiritide in Hypertension (TENSE1). ClinicalTrials.gov. 2021 [cited 21 Jun 2021]. https://clinicaltrials.gov/ct2/show/NCT02 608996.

107. Vaidya A, Williams JS. The relationship between vitamin $\mathrm{D}$ and the renin-angiotensin system in the pathophysiology of hypertension, kidney disease, and diabetes. Metabolism. 2012;61(4):450-8.

108. Cao Y, Lu L, Liang J, Liu M, Li X, Sun R, Zheng Y, Zhang P. Omega-3 fatty acids and primary and secondary prevention of cardiovascular disease. Cell Biochem Biophys. 2015;72(1):77-81.

109. Vitamin D and Omega-3 Hypertension Trial (VITAL Hypertension). ClinicalTrials.gov. 2021 [cited 21 Jun 2021]. https://clini caltrials.gov/ct2/show/NCT01653678.

110. Clinical Efficacy and Safety Evaluation of HCP1904-1 in Essential Hypertension Patients. ClinicalTrials.gov. 2021 [cited 21 Jun 2021]. https://clinicaltrials.gov/ct2/show/NCT04820907.

111. Clinical Trial to Evaluate the Efficacy and Safety of CKD-333 Tablet. ClinicalTrials.gov. 2021 [cited 21 Jun 2021]. https://clini caltrials.gov/ct2/show/NCT03583905.

112. Cai G, Zheng Y, Sun X, Chen X. Prevalence, awareness, treatment, and control of hypertension in elderly adults with chronic kidney disease: results from the survey of Prevalence, Awareness, and Treatment Rates in Chronic Kidney Disease Patients With Hypertension in China. J Am Geriatr Soc. 2013;61(12):2160-7.

113. Kidney Disease: Improving Global Outcomes (KDIGO) Blood Pressure Work Group. Clinical practice guideline for the evaluation and management of blood pressure in chronic kidney disease. Kidney Int Suppl. 2012;2(5):337-414.

114. Holtkamp FA, de Zeeuw D, Thomas MC, et al. An acute fall in estimated glomerular filtration rate during treatment with losartan predicts a slower decrease in long-term renal function. Kidney Int. 2011;80:282-7.

115. Ku E, Lee BJ, Wei J, Weir MR. Hypertension in CKD: core curriculum 2019. Am J Kidney Dis. 2019;74(1):120-31.

116. Steuber TD, Lee J, Holloway A, Andrus MR. Nondihydropyridine calcium channel blockers for the treatment of proteinuria: a review of the literature. Ann Pharmacother. 2019;53(10):1050-9.

117. Simonson DC. Etiology and prevalence of hypertension in diabetic patients. Diabetes Care. 1988;11(10):821-7.

118. Ong HT, Rozina G. Selecting antihypertensive medication in patients with essential hypertension in Malaysia. Med J Malaysia. 2009;64(1):3-11.

119. Palmer SC, Mavridis D, Navarese D, Craig JC, Tonelli M, Salanti G, et al. Comparative efficacy and safety of blood pressurelowering agents in adults with diabetes and kidney disease: a network meta-analysis. Lancet. 2015;385(9982):2047-56.

120. Jiang SZ, Lu W, Zong XF, Ruan HY, Liu Y. Obesity and hypertension. Exp Ther Med. 2016;12(4):2395-9.

121. Grassi G. How to treat hypertension in the obese. e-J Cardiol Pract. 2013; 12(2).

122. Scholze J, Grimm E, Herrmann D, Unger T, Kintscher U. Optimal treatment of obesity-related hypertension: the Hypertension-Obesity-Sibutramine (HOS) study. Circulation. 2007;115(15):1991-8.

123. Kawarazaki W, Fujita T. The role of aldosterone in obesityrelated hypertension. Am J Hypertens. 2016;29(4):415-23.

124. Buglioni A, Cannone V, Cataliotti A, Sangaralingham SJ, Heublein DM, Scott CG, et al. Circulating aldosterone and natriuretic peptides in the general community: relationship to cardiorenal and metabolic disease. Hypertension. 2015;65(1):45-53.

125. Morales E, Gutiérrez E, Caro J, Sevillano A, Rojas-Rivera J, Praga M. Beneficial long-term effect of aldosterone antagonist added to a traditional blockade of the renin-angiotensin-aldosterone system among patients with obesity and proteinuria. Nefrologia. 2015;35(6):554-61. 